Emovon I, Norman RA, Murphy AJ.

The development of a model for determining scheduled replacement

Intervals for marine machinery systems.

Proceedings of IMechE, Part M: Journal of Engineering for the Maritime

Environment 2016

DOI: http://dx.doi.org/10.1177/1475090216681345

\section{Copyright:}

This is the authors' accepted manuscript of an article that was published in its final definitive form by Sage, 2016.

DOI link to article:

http://dx.doi.org/10.1177/1475090216681345

Date deposited:

$13 / 01 / 2017$

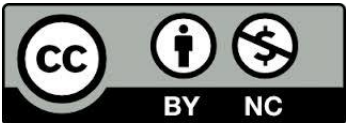

This work is licensed under a Creative Commons Attribution-NonCommercial 3.0 Unported License 


\title{
The development of a model for determining scheduled replacement Intervals for marine machinery systems
}

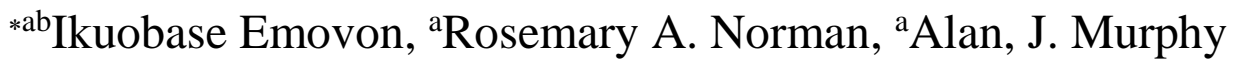 \\ a School of Marine Science and Technology, Newcastle University, Newcastle upon Tyne, \\ NE1 7RU, UK \\ ${ }^{\mathrm{b}}$ Department of Mechanical Engineering, Federal University of Petroleum Resources, Effurun, \\ Nigeria \\ Email: [ i.emovon ; rose.norman ; a.j.murphy]@newcastle.ac.uk
}

\begin{abstract}
One of the challenges of maintenance management of a marine machinery system is the problem of selecting the optimum interval for replacement of equipment items. Most of the approaches that are given in the literature for selecting optimum replacement intervals are based on a single criterion model such as cost. This approach may be satisfactory for some industries but for the marine industry disruption in services will result in a considerable cost penalty and, as such, other factors such as system downtime and system reliability must be taken into consideration when determining the optimum replacement interval for the system. These decision criteria have been proven to be in conflict with one another. On this basis, a Multi-Criteria Decision Making (MCDM) tool, TOPSIS, is proposed in this paper for aggregating multiple criteria in order for them to be used simultaneously in determining the optimum scheduled replacement interval for the equipment items of the system. The use of a multi-criteria decision making tool allows the decision maker to express preference for the decision criteria in terms of their levels of importance. To achieve this aim a compromise decision weighting technique is integrated with TOPSIS. The compromise weighting technique was obtained from a combination of the variance method (an objective decision criteria weighting technique) and Analytical Hierarchy Process (AHP) (a subjective decision criteria weighting technique). In order to demonstrate the applicability of the proposed innovative methodology for determining the optimum replacement intervals for a marine machinery system and also validate the technique, a case study involving some equipment items of a marine diesel engine is presented. Although results show that it produces the same optimum solution as the methods in the literature, the proposed method is more flexible and less computationally intensive.
\end{abstract}

\footnotetext{
*Corresponding author, Email address: i.emovon@newcastle.ac.uk, ikuoy2k@yahoo.com ( I. Emovon)
} 
Keywords: Marine machinery system. Replacement interval. Decision criteria. TOPSIS

\section{Introduction}

The shipping industry is a very competitive environment and for any company to remain in business, an efficient and reliable service must be provided to its customers. This can only be achieved if ships are safely and efficiently operated. The safety and reliability of the ship system however depend on the effectiveness of the maintenance scheme in place for preserving or restoring equipment items. From accident data analysis performed on data collected from fishing vessels from 1994-1999 it was observed that over 50\% of accidents were caused by machinery failures. ${ }^{1}$ This shows how important the marine machinery system is to the entire ship system with respect to its safe and reliable operation. In order to increase ship availability and at the same time reduce the chances of ship accidents, at minimum cost, concerted effort must be made to ensure that the maintenance of marine machinery system equipment items is optimised. $^{2}$

Maintenance is defined as a combination of activities to retain a component in, or restore it to, a state in which it can perform its designated functions. ${ }^{3}$ There are basically two maintenance approaches; corrective maintenance and preventive maintenance. In the corrective maintenance approach, equipment or systems are allow to run until failure occurs before they are fixed while preventive maintenance is performed either based on a definite time interval or based on the condition of the system. For some equipment items of the ship system, time based preventive maintenance is more appropriate for mitigating or eliminating failure. Time based preventive maintenance involves the process of repair or replacement activities being performed at regular intervals. Hence scheduled replacement is one of the techniques that is used in preventive maintenance in order to recover the functions of an equipment item. Bahrami-G and Price ${ }^{4}$ defined it as a practice that entails decision making, based on certain criteria regarding the optimal time to replace an equipment item so as to reduce or eliminate a sudden breakdown. Generally two conditions must be satisfied to justify the use of a scheduled replacement as the strategy in maintaining equipment. These are: (1) the value of the Weibull shape parameter, $\beta$, of the equipment/ components statistical variability must be greater than 1 and (2) the cost of the replacement activity as a result of failure must be greater than cost of a planned replacement.

One of the greatest challenges of this preventive maintenance approach is the selection of the optimum interval to perform preventive maintenance tasks on equipment items. ${ }^{5}$ This because, if the intervals are not properly timed, it can result in over-maintenance and a waste of resources 
and man hours due to premature replacement of equipment items or, an even worse case scenario, under-maintenance can result in catastrophic failure and invariably production loss and the company's image being damaged. This makes the subject of interval selection for preventive maintenance an important task worthy of thorough investigation.

Most of the approaches used in the literature are based on single criteria for both land-based and marine systems. These approaches may not be sufficient in arriving at optimum solution since the decision making process involves many decision criteria such as cost and reliability. However only limited studies are found on the use of multi-criteria in obtaining appropriate equipment item replacement intervals for land based system with none for marine systems. In addition, the multi-criteria approaches available in the literature all have one limitation or another. Hence the purpose of this paper is to develop a systematic approach for determining appropriate replacement intervals for marine systems using a multi-criteria approach that is easier to apply than those used in the literature for land based system.

The paper is organised as follows: Section 2 reports a literature review of MCDM techniques for maintenance management. Section 3 outlines the proposed scheduled replacement interval determination methodology. In Section 4 the case of the marine diesel engine is presented. Finally the conclusions are presented in Section 5.

\section{Literature Review}

Plant equipment classically utilizes two types of maintenance management approach: run-tofailure or preventive maintenance. ${ }^{6-8}$ The preventive maintenance approach could be timebased or condition-based. Time-based preventive maintenance is of two types; scheduled replacement and scheduled overhaul while condition-based maintenance is also of two types; periodic and continuous condition monitoring. ${ }^{9}$ To select the maintenance approach suitable for plant systems, MCDM techniques have been used in literature. Goossens and Basten ${ }^{10}$ used AHP to determine suitable maintenance approaches for marine systems. Once the maintenance approach is determined, the next step is to determine the interval for performing the maintenance task and that is the focus of this paper. Specifically the determination of the appropriate interval for performing the scheduled replacement type of time-based preventive maintenance.

From the literature two popular models have generally been applied; the Age Replacement Model (ARM) and the Block Replacement Model (BRM). ${ }^{11}$ For the ARM, an equipment item 
is replaced either at a predetermined age or at failure. For the block replacement model, however equipment/components are replaced at constant time intervals and in the case of failure before the constant time interval has elapsed the equipment/components are replaced and will be replaced again once the same constant time interval has passed.

Huang and Miller ${ }^{12}$ developed a standard solution for the ARM that was proposed by Barlow and Hunter ${ }^{13}$ and, for ease of use of its solution technique, it was organised in the form of tables and charts. Another important feature of the standard solution, in addition to organising it in tables, is in the reduction of input parameters by using a cost ratio in place of the actual cost of failure replacement $\left(C_{a}\right)$ and cost of preventive replacement $\left(C_{b}\right)$. The algorithm developed for the standard solution technique has been applied to various examples in order to demonstrate the applicability of the technique. In their paper, Cheng and Tsao ${ }^{14}$ applied the standard solution for the determination of the preventive replacement maintenance interval for a rolling stock component. Das and Acharya ${ }^{15}$ presented two age-based replacement models for preventative replacement of an equipment item. The two preventive replacement policies included consideration of the equipment failure delay time (the time between the point of equipment failure initiation and the point at which the equipment eventually failed). In the first model, the trend of the degradation of the equipment during the delay time was utilised in order to determine the preventive replacement interval. Hence, for this policy, replacement due to failure or prevention of failure is performed after a fixed period during its delay time. The second policy, according to the authors, is an opportunistic age replacement technique where a failing equipment item or component is replaced at the next available maintenance opportunity. Finally the authors opined that the two policies, although designed for a single unit system, were capable of addressing a multi-unit system when there is difficulty in tracking the whole life of each individual equipment item or component. Jiang and $\mathrm{Ji}{ }^{16}$ investigated the relationship between the preventive effect produced from alternative replacement intervals and corresponding cost savings. The preventive replacement models that they studied were the age and the block preventive replacement models. From the results, reasonable cost savings can be derived if the system is replaced when it has reached satisfactory age. The authors also opined that the often increasing failure rate of the equipment or components does not necessarily translate to representing 'satisfactory age' and this has to be determined by the maintenance practitioners based on the maintenance goal.

Ahmad and Kamaruddin ${ }^{17}$ utilised the age based model that was developed by Hunter and Barlow in revising the preventive replacement interval for a production machine in the processing industry. The important feature of their approach was the consideration of the covariate effect on the life of the machine. In the real sense, the actual state of the machine was considered in the determination of the preventive replacement interval of the machine. The 
authors compared the revised replacement interval (inclusion of the covariate effect) with the replacement interval (without covariate effect). From the result, the revised preventive replacement interval and the replacement interval without the covariate effect differed considerably. While the revised method produced a 21 day interval for replacement of the production machine, the replacement interval without the covariate effect produced a 35 day interval. Bahrami-G and Price ${ }^{4}$ presented a new model for the preventive replacement of an equipment item or component that is experiencing an increasing failure rate. The model proposed is a simplified version of the BRM. A case study of an equipment item whose failure rate followed a normal distribution was applied to determine the benefits and suitability of the technique. According to the authors, the results obtained from the model almost perfectly matched the result from that of Hunter and Barlow whose approach is more computationally challenging. They concluded that the proposed model will aid the maintenance practitioner to make more cost-effective decisions. In all of the ARM and BRM models described above, the authors utilised a single criterion either cost or downtime in determining the optimum interval for carrying out scheduled replacement of equipment items. However the use of a single decision criterion may not be appropriate for some systems especially marine systems whose failure can result in severe consequences on personnel, equipment and environment that may not be reversible. Additionally, conflicting multi-criteria are generally associated with the decision making process. For such a system, multi-criteria should be applied in making maintenance decisions and in analysing such problems MCDM tools are used.

There are some limited studies that deal with the use of the MCDM approach to selecting intervals for preventive maintenance tasks ${ }^{18,19}$ but they were applied for land based systems with no applications reported for maritime systems. Cavalcante and De Almeida ${ }^{20}$ presented a preventive maintenance decision model based on a combination of PROMETHEE II (PROMETHEE is an acronym for Preference Ranking Organisation METHod for Enrichment Evaluations) and Bayesian technique considering two decision criteria; cost and reliability. In a similar work Cavalcante and Ferreira ${ }^{21}$ also proposed an integrated PROMETHEE based methodology combined with Bayesian technique and, in addition, accounting for possible uncertainty in maintenance data. Chareonsuk and Nagarur ${ }^{19}$ also proposed a PROMETHEE multi-criteria decision making methodology for the selection of preventive maintenance intervals. The authors applied the Huang and Miller ${ }^{12}$ assumption that corrective replacement cost and preventive replacement cost can be in the form of a ratio in the case of a situation with a lack of data. The cost ratio was then varied for different assigned alternative replacement maintenance intervals in the expected cost replacement model in order to obtain corresponding values of cost and reliability factors. Finally PROMETHEE was applied in ranking alternative preventive maintenance intervals with respect to the evaluated decision criteria namely maintenance cost and reliability. The authors chose the maintenance interval with the best 
PROMETHEE index. The PROMETHEE technique used by these authors, has the challenge of problem structuring thereby making the evaluation procedure complicated as the number of decision criteria increases especially when more than seven decision criteria are used ${ }^{22}$. This approach will limit maintenance practitioners' choice of decision criteria for selecting optimum preventive maintenance intervals. Additionally the authors' approach for weighting decision criteria lacked flexibility as it only depended on subjective rules without balancing it with an objective technique or using a compromise between them. The above approach, may be ideal for land based system but is not appropriate for marine systems which operate in a harsh environment and whose equipment failure may result to both loss of an entire vessel and crew members. Finally, since ships operates in isolated environment, the use of the PROMETHEE technique with lots of computational issues especially when more than seven decision criteria are involved in the decision making process, may not be attractive to maintenance practitioners on-board a ship.

From this literature review it is obvious that there is need to develop a more systematic approach for marine systems which will meet the environmental maintenance need and also satisfy the requirement of the regulatory bodies. Hence this paper proposes an integrated system of TOPSIS with a compromise weighting technique for determination of optimum scheduled replacement intervals. While TOPSIS is applied in the ranking of alternative scheduled replacement intervals, the compromise weighting technique is used for determining inspection interval weights. The crux of the TOPSIS methodology is the determination of relative closeness to different scheduled replacement interval alternatives with respect to the ideal solution. The alternatives are ranked based on this relative closeness to the ideal solution. The method was first introduced in 1981 by Hwang and Yoon ${ }^{23}$. The technique is capable of solving a decision problem whilst utilising a number of decision criteria without much computational effort or burden of preference function determination for decision criteria and thereby avoiding the limitations of the PROMETHEE technique utilised by previous authors for ranking replacement interval alternatives. To make the decision process more flexible, the compromise weighting technique was integrated into it such that the maintenance practitioners can either use a subjective approach or an objective approach or a combination of the two in determining decision criteria weights.

The proposed methodology avoids the limitations of the MCDM approach that had been applied in the literature for land-based system applications. 


\section{Proposed scheduled replacement interval determination methodology}

The proposed methodology is based on the integration of MCDM techniques with Age Replacement Models. The aim of the proposed MCDM approach was to avoid the limitations which are typically present in the methods used for land-based systems because of the specific issues associated with the ship-board operations, namely limited access to specialists and highperformance computational facilities. To achieve this, TOPSIS (Technique for Order Preference by Similarity to an Ideal Solution) was used in place of PROMETHEE which is typically applied in land-based systems. The decision to do this was based on the fact that PROMETHEE presents significant challenges with regard to decision problem structuring and evaluation procedure complexity when more than seven decision criteria are used where as TOPSIS can be used in a relatively straight-forward manner, to arrive at an optimum solution regardless of the number of decision criteria. The use of TOPSIS also avoids putting an additional burden on maintenance practitioners of determining the preference function associated with the PROMETHEE method.

Furthermore, since the key factors that influence the selection of intervals are the decision criteria, an efficient framework which integrates subjective and objective criteria weighting techniques is introduced for evaluating weights of criteria as opposed to the use of only subjective techniques identified for land-based system applications in the literature. The weighting framework is flexible and it allows maintenance practitioners to either use subjective criteria weighting techniques or objective weighting techniques or a combination of the two.

\subsection{Weibull distribution}

The Weibull distribution comes in 1, 2 and 3 parameter versions and for this work the 2 parameter version was adopted because it is generally used in modelling the failure behaviour of most practical systems, due to its versatility in fitting different failure patterns. ${ }^{24,25}$

The two parameter Weibull distribution probability density function is defined as follows:

$$
f(t)=\frac{\beta}{\emptyset}\left(\frac{t}{\emptyset}\right)^{\beta-1} \exp \left[-\left(\frac{t}{\emptyset}\right)^{\beta}\right]
$$

Where $\mathrm{t} \geq 0, \varnothing>0$ and $\beta>0$ 
$\beta$ is the shape parameter which express the form of the distribution and $\varnothing$ is the scale parameter which influences the spread of the distribution.

\subsubsection{Parameter estimation}

Several techniques such as probability plotting, regression analysis, method of moment and maximum likelihood estimation have been developed for determining parameters $\varnothing$ and $\beta$ that will fit a distribution to a particular data set. The choice of method is dependent on the data type collected and in some scenarios the type of distribution selected. When a complete set of data for machinery is available, regression analysis is generally more appropriate. However, in most real life situations, that may not be realistic as data is subjected to censoring. The maximum likelihood technique is usually the most suitable for analysing a data set with a relatively large amount of censoring. ${ }^{26}$

\section{Maximum likelihood estimation}

The maximum likelihood estimation technique can be used to obtain parameters for any distribution such as a Weibull distribution that will best describe the given failure data.

Consider $\mathrm{T}$ as a continuous random variable with probability density function $f\left(t_{i}, \theta_{1}, \theta_{2}, \ldots, \theta_{k}\right)$, where $\theta$ are the parameters of the distribution which are candidates for evaluation and $t_{1}, t_{2}, \ldots, t_{n}$ are failure time data collected for the machinery system. The likelihood function $(L)$ is determined as follows: ${ }^{26,27}$

$L=\prod_{i=1}^{n} f\left(t_{i} ; \theta_{1}, \theta_{2}, \ldots, \theta_{k}\right)$

Where $n$ is the failure data sample size and $k$ is the number of Weibull parameters.

L or the natural logarithm of it is then partially differentiated with respect to $\theta_{1}, \theta_{2}, \ldots, \theta_{k}$ which will then result in equations for obtaining the estimated values of $\theta_{1}, \theta_{2}, \ldots, \theta_{k}$. The partial derivative of the natural logarithm $\mathrm{L}$ is as follows:

$\frac{\partial \ln L}{\partial \theta_{j}}=0 \quad j=1,2, \ldots, k$

This technique may be illustrated through application to the probability density function of a 2 parameter Weibull distribution function given in Eq. (1) to estimate the Weibull parameters $\emptyset$ and $\beta$, as presented in the work of Cohen ${ }^{26}$ and Al-Fawzan ${ }^{27}$. This is as follows: 
$L\left(t_{1}, t_{2}, \ldots, t_{k} ; \beta, \varnothing\right)=\prod_{i=1}^{n} \frac{\beta}{\emptyset}\left(\frac{t_{i}}{\emptyset}\right)^{\beta-1} \exp \left[-\left(\frac{t_{i}}{\varnothing}\right)^{\beta}\right]$

The logarithm of Eq. (4) was taken and partially differentiated with respect to $\varnothing$ and $\beta$ respectively and equated to zero which resulted in Eq. (5) and (6).

$$
\begin{aligned}
& \frac{\partial \ln L}{\partial \beta}=\frac{n}{\beta}+\sum_{i=1}^{n} \ln t_{i}-\frac{1}{\emptyset} \sum_{i=1}^{n} t_{i}^{\beta} \ln t_{i}=0 \\
& \frac{\partial \ln L}{\partial \emptyset}=-\frac{n}{\emptyset}+\frac{1}{\emptyset^{2}} \sum_{i=1}^{n} t_{i}^{\beta}=0
\end{aligned}
$$

Equation (5) and (6) may be reduced to Eq. 7 by eliminating $\varnothing$ between them and simplifying.

$$
\frac{\sum_{i=1}^{n} t_{i}^{\beta} \ln t_{i}}{\sum_{i=1}^{n} t_{i}^{\beta}}-\frac{1}{\beta}-\frac{1}{n} \sum_{i=1}^{n} \ln t_{i}=0
$$

From here the first step is to evaluate $\beta$ using a standard iterative procedure such as the NewtonRaphson method. Finally $\emptyset$ is determined using Eq. (7) which produces

$$
\emptyset=\frac{\sum_{i=1}^{n} t_{i}^{\beta}}{n}
$$

\subsection{Criteria function}

The scheduled replacement interval selection decision making is based on decision criteria generally defined by the maintenance managers. In this study, as previously stated, cost, reliability and maintenance down time are the criteria upon which the optimum interval will be selected. Two factors that influence the selection process are the weights and values of the criteria. In assigning values to criteria, experts' opinion is relied on in the face of a lack of, or limited, reliable failure data and that approach is qualitative. However the concern here is that the quantitative approach relies heavily on data availability. Quantitative mathematical functions are used in evaluating decision criteria as follows: 
Reliability function: The probability that a system will survive to a particular time $t$, is referred to as reliability. ${ }^{28}$ The reliability function is thus represented as follows:

$R\left(t_{p}\right)=\int_{t_{p}}^{\infty} f(t) d t$

Substituting Eq. (1) into Eq. (9) the two parameter Weibull form of the reliability function is defined as

$R\left(t_{p}\right)=\exp \left[-\left(\frac{t_{p}}{\emptyset}\right)^{\beta}\right]$

Cost function: : Cost models have been developed to represent different replacement decisions; in the case of the present work, the cost model takes into account the time required to effect a replacement both in the preventive case and in the event of failure: ${ }^{29}$

$C\left(t_{p}\right)=\frac{C_{a}\left(1-R\left(t_{p}\right)\right)+C_{b} R\left(t_{p}\right)}{\int_{0}^{t_{p}} t f(t) d t+T_{a}\left(1-R\left(t_{p}\right)\right)+\left\{\left(T_{b}+t_{p}\right) R\left(t_{p}\right)\right\}}$

Where:

The numerator is the expected cost per cycle and the denominator is the expected cycle time;

$\mathrm{C}_{\mathrm{a}}$ is the cost of unit failure maintenance

$\mathrm{C}_{\mathrm{b}}$ is the cost of unit preventive maintenance

$t_{p}$ is the given scheduled replacement interval

Downtime function: Downtime is given by Jardine ${ }^{29}$

$D\left(t_{p}\right)=\frac{T_{b}\left(1-R\left(t_{p}\right)\right)+T_{a} R\left(t_{p}\right)}{\int_{0}^{t_{p}} t f(t) d t+T_{b}\left(1-R\left(t_{p}\right)\right)+\left\{\left(T_{a}+t_{p}\right) R\left(t_{p}\right)\right\}}$

Where:

$\mathrm{T}_{\mathrm{b}}$ is the time taken for unit failure maintenance

$\mathrm{T}_{\mathrm{a}}$ is the time taken for unit preventive maintenance 
$\mathrm{R}, \mathrm{C}$ and $\mathrm{D}$, together with the alternatives' preventive maintenance interval $\left(t_{p}\right)$ are then used to form a decision table. The decision table formed is presented in Table 1 where $\mathrm{R}, \mathrm{C}$ and $\mathrm{D}$ are represented as $B_{j}(j=R, C \& D)$ and the alternative scheduled replacement intervals are represented as $A_{i}(i=1,2 \ldots, m)$ while the measure of performance of the alternative scheduled replacement interval is represented as $X_{i j}$. A discrete set of maintenance intervals was used rather than a continuous data set because maintenance experts would typically estimate maintenance periods in fixed intervals based on equipment manufacturer manuals rather than in terms of an absolute number of running hours. Having formed the decision table, the next task is to explore different multi-criteria decision making (MCDM) techniques for determining the optimum alternative scheduled replacement task interval.

Table 1: Decision matrix

\begin{tabular}{|c|c|c|c|}
\hline \multirow[t]{2}{*}{ Alternatives $\left(A_{i}\right)$} & \multicolumn{3}{|c|}{ Decision criteria $\left(B_{j}\right)$} \\
\hline & $\mathrm{R}$ & $\mathrm{C}$ & $\mathrm{D}$ \\
\hline $\mathrm{A}_{1}$ & $\mathrm{x}_{11}$ & $\mathrm{x}_{12}$ & $\mathrm{x} 13$ \\
\hline $\mathrm{A}_{2}$ & $\mathrm{x}_{21}$ & $\mathrm{x}_{22}$ & $\mathrm{x} 23$ \\
\hline $\mathrm{A}_{3}$ & $x_{31}$ & $\mathrm{x}_{32}$ & $\mathrm{x} 33$ \\
\hline- & - & - & - \\
\hline- & - & - & - \\
\hline $\mathrm{A}_{m}$ & $\mathrm{x}_{\mathrm{ml}}$ & $\mathrm{x}_{\mathrm{m} 2}$ & $\mathrm{x}_{\mathrm{m} 3}$ \\
\hline
\end{tabular}

\subsection{Criteria weighting model}

After the formation of the decision table or matrix the next step is to determine the weight of the decision criteria ( $\mathrm{R}, \mathrm{C}$ and $\mathrm{D})$. Previous authors who have used the MCDM approach in determining the most appropriate time interval for scheduled replacement tasks have only assumed weight for decision criteria in their analysis (for example see the work of Cavalcante and Ferreira ${ }^{21}$ and Chareonsuk and Nagarur ${ }^{19}$ ), forgetting the fact that the weight of decision criteria is a critical factor in arriving at the appropriate scheduled replacement time interval. On the basis of the criticality of this factor, two different decision criteria weighting techniques; the variance method and the Analytical Hierarchy Process (AHP) method were considered. While the variance method is an objective weighting technique, the AHP method is a subjective weighting technique.

\subsubsection{Analytical Hierarchy Process (AHP)}

AHP basically involves reducing complex decisions to a series of simple pairwise comparisons and rankings, and then synthesizing the results to obtain an overall ranking. Wang and $\mathrm{Wu}^{30}$ 
have used the technique to evaluate decision criteria weights for programmable logic controller decision problems. The use of AHP has been considered here because it has been applied in solving similar multi-criteria decision problems and also its ability to utilise qualitative information in the decision making process. This makes it capable of addressing the subjective need of the proposed compromise weighting technique. The steps for AHP analysis, as presented in Caputo and Pelagagge ${ }^{31}$, with revision are as follows:

(1) AHP questionnaires are produced for $z$ experts to carry out pair-wise comparison judgement with respect to the relative importance among the $n$ decision criteria. An $n \times n$ pairwise comparison matrix $A^{k}$ is formed, where $k=1,2, \ldots, \mathrm{z}$, from each individual expert's judgements which is expressed as follows: ${ }^{32}$

$A^{k}=\left[a_{i j}^{k}\right]_{n x n}=\left[\begin{array}{cccc}a_{11}^{k} & a_{12}^{k} & \ldots & a_{1 n}^{k} \\ a_{21}^{k} & a_{22}^{k} & \ldots & a_{2 n}^{k} \\ \vdots & \vdots & \ddots & \vdots \\ a_{n 1}^{k} & a_{n 2}^{k} & \ldots & a_{n n}^{k}\end{array}\right]$

Where

$a_{i j}^{k}>0, a_{i j}^{k}=1 / a_{j i}^{k}, \quad a_{i i}^{k}=1$

$a_{i j}^{k}$ is the assigned rating by k-th expert of the relative importance of criterion $i$ over that of criterion $j$. For example if criteria $i$ and $j$ are of equal importance $a_{i j}^{k}=a_{j i}^{k}=1$. The AHP scale developed by Saaty used in the rating of decision criteria and is shown in Table 2.

Table 2: AHP importance scale ${ }^{33}$

\begin{tabular}{ll}
\hline Score & Relative importance \\
\hline 1 & criteria $i$ and $j$ are of equal importance \\
3 & criteria $i$ is slightly more important than \\
criterion $j$ & criteria $i$ is significantly more important than \\
criterion $j$ & criteria $i$ is strongly more important than \\
5 & criterion $j$ \\
7 & criteria $i$ is extremely more important than \\
criterion $j$
\end{tabular}

Note: $2,4,6$ and 8 are intermediate values 
(2) The weights of each criterion $C_{1}, C_{2}, \ldots, C_{n}$ are then evaluated as follows:

$w_{i}^{k}=\frac{1}{n} \sum_{j} \frac{a_{i j}^{k}}{\sum_{i} a_{i j}^{k}}$

Where $w_{i}^{k}$ is the weight of criteria $C_{i}$

The decision criteria weights are generally represented as a weight vector $\left(\mathbf{W}^{\mathbf{k}}\right)$ expressed as follows.

$\boldsymbol{W}^{\boldsymbol{k}}=\left[w_{1}^{k}, \quad w_{2}^{k}, \ldots, w_{n}^{k}\right]^{T}$

(3) The consistency of judgement by the experts is then evaluated using the consistency ratio $I_{r}$. For expert pairwise comparison judgement to be acceptable, the evaluated consistency ratio must be less than or equal to 0.1 and if the value is greater than this, it is generally advisable for the experts to revise their initial pairwise comparison judgement ${ }^{33}$. The consistency ratio is calculated as:

$I_{r,}=\frac{S I}{R I}$

Where RI is the equivalent average random value of $S I$ for an $n \times n$ matrix, the values for which are presented in Table 3 , and SI is the consistency index and can be evaluated as

$S I=\frac{\lambda_{\max }-n}{n-1}$

Where $\lambda_{\max }$ is the maximum eigenvalue

$$
\lambda_{\max }=\frac{1}{n} \sum_{i=1}^{n} \frac{\left(A w^{k}\right)_{i}}{w_{i}^{k}}
$$

Table 3: RI values for different matrix order ${ }^{33}$

\begin{tabular}{llllllll}
\hline $\mathrm{n}$ & 1 & 2 & 3 & 4 & 5 & 6 & 7 \\
\hline $\mathrm{RI}$ & 0 & 0 & 0.52 & 0.89 & 1.11 & 1.25 & 1.35 \\
\hline
\end{tabular}




\subsubsection{Statistical variance method}

Using the statistical variance method in evaluating the weight of decision criteria, the methodological steps are as follows: ${ }^{34,35}$

1. Normalisation of the decision matrix.

The decision matrix formed is normalised as follows:

$q_{i j}=\frac{x_{i j}}{\sum_{i=1}^{m} x_{i j}}, \quad i=1,2, \ldots, m ; j=1,2, \ldots, n$

Where $q_{i j}$ is the normalised decision matrix.

2. Determination of variance of individual decision criteria.

The variance of each decision criterion is calculated as follows:

$S V_{j}=\frac{1}{m}\left[\sum_{i}^{m}\left(q_{i j}-\bar{q}_{i j}\right)^{2}\right]$

Where $\bar{q}_{i j}$ is the mean value of $q_{i j}$

$S V_{j}$ is the variance of each risk criterion.

3. Determine decision criteria weights.

Finally the decision criteria weights are determined as follows:

$w_{j}^{v}=\frac{S V_{j}}{\sum_{j}^{n} S V_{j}}$

Where $w_{j}^{v}$ is the weight of the decision criteria.

\subsubsection{Compromised weighting method:}

In order to have a balanced weighting technique, the two methods were integrated to develop a compromised weighting technique. If only the variance method was used then there would be the potential for the weighting to be skewed by the spread of the matrix data however, the compromised weighting method limits that effect by including expert opinion within the weighting process ${ }^{45}$. The integrated weighting technique produced by combining the variance method and AHP method is presented as follows: 
$w c_{j}=\frac{\emptyset A_{j} \cdot w_{j}^{v}}{\sum_{j=1}^{n} \emptyset A_{j} \cdot w_{j}^{v}} \quad j=1, \ldots, n$

Where $\varnothing A_{j}$ is the weight of criteria obtained by AHP method,

$w_{j}^{v}$ is the weight of criteria obtained by variance method.

$w c_{j}$ is the compromised decision criteria weighting method.

\subsection{TOPSIS: Preventive maintenance interval alternatives ranking tool}

The methodological steps for TOPSIS analysis, as presented in the work of Emovon et al. ${ }^{36}$ and Khorshidi and Hassani ${ }^{37}$ are as follows:

(1) Determination of the weighted normalised decision matrix:

The weighted normalised decision matrix can be calculated by multiplying the normalised decision matrix by the weight of decision criteria and is expressed as:

$v_{i j}=w_{j} q_{i j}, \quad i=1, \ldots, m ; j=1, \ldots, n$

Where $w_{j}$ is the weight of the $j t h$ criterion.

(2) Determination of the positive-ideal and negative-ideal solutions.

The best value of each weighted criterion is the positive ideal solution, while the worst value of each weighted criterion is the negative ideal solution and these are evaluated as follows:

$$
\begin{array}{ll}
\left\{v_{1}^{+}, v_{2}^{+}, \ldots, v_{n}^{+}\right\}=\left\{\left(\max _{i} v_{i j} \mid j \epsilon I\right),\left(\min _{i} v_{i j} \mid j \epsilon I^{\prime}\right)\right\} & i=1,2, \ldots, m \\
\left\{v_{1}^{-}, v_{2}^{-}, \ldots, v_{n}^{-}\right\}=\left\{\left(\min _{i} v_{i j} \mid j \epsilon I\right),\left(\max _{i} v_{i j} \mid j \epsilon I^{\prime}\right)\right\} & i=1,2, \ldots, m
\end{array}
$$

Where $I$ is associated with the benefit criteria and $I^{\prime}$ is associated with cost criteria

(3) Evaluation of the separation measure.

The separation of each scheduled replacement interval alternative from the positive-ideal solution, $S S_{i}^{+}$, and from the negative-ideal solution, $S S_{i}^{-}$, are expressed, respectively as: 


$$
\begin{aligned}
& S S_{i}^{+}=\left\{\sum_{j=1}^{n}\left(v_{i j}-v_{j}^{+}\right)^{2}\right\}^{\frac{1}{2}} i=1,2 \ldots . m ; j=1,2, \ldots, n \\
& S S_{i}^{-}=\left\{\sum_{j=1}^{n}\left(v_{i j}-v_{j}^{-}\right)^{2}\right\}^{\frac{1}{2}} i=1,2, \ldots, m ; j=1,2, \ldots, n
\end{aligned}
$$

(4) Evaluation of the relative closeness to the positive ideal solution.

The relative closeness $d p_{i}$ of each scheduled replacement interval to the positive ideal solution is calculated as:

$d p_{i}=\frac{S S_{i}^{-}}{S S_{i}^{+}+S S_{i}^{-}}, \quad i=1, \ldots, m$

The $d p_{i}$ value is the performance index of the scheduled replacement interval alternatives. The scheduled replacement interval alternative with the highest performance index is the optimum solution.

\subsection{Procedure for applying the proposed methodology}

The flow chart of the proposed methodology is presented in Figure 1 and the steps are discussed as follows:

Step 1 and Step 2: the possible scheduled replacement interval alternatives and the decision criteria for selecting the alternatives are identified by the team based on experience, literature and equipment manufacturers' manuals. The optimum interval is then selected based on the preferred criteria. The criteria that may be considered are cost, reliability, availability, maintainability, spare parts inventory, quality issues and maintenance downtime. ${ }^{19}$ In this research, maintenance cost, reliability and maintenance downtime were considered. The maintenance cost criterion was chosen because it constitutes a major portion of the operating cost of the ship system. However in minimising cost, adequate care must be taken not to compromise the reliability of the system. This is because if the reliability of the system is compromised, it can result in catastrophic failure that may have irreversible damage on 
personnel, equipment and the environment. This makes reliability an important criterion that must not be ignored in selecting the optimum replacement interval for ship machinery systems. The downtime criterion was also chosen because downtime of equipment can produce detrimental penalties. For example, for a ship carrying perishable goods, the goods can be spoilt and this can result in the ship operator compensating the owners of the goods. Furthermore the image of the company can also be badly damaged.

Step 3. Data availability is central to the successful selection of the optimum interval for scheduled replacement activities and as such data should be collected for the system being investigated. However, for equipment which deteriorates with time such as marine machinery systems, a Weibull distribution is generally applicable to fit the collected failure data ${ }^{38}$. On this basis a Weibull distribution function was assumed in this study. The Weibull distribution is then applied to the component failure data in evaluating the scale parameter, $\emptyset$, and the shape parameter, $\beta$. Apart from time-to-failure, cost and downtime data are also essential for decision criteria evaluation.

Steps 4-6. For each scheduled replacement interval alternative, decision criteria values are determined using decision criteria models in Eq. 10, 12 and 13. The decision criteria were modelled in this research using the Age Replacement Model (ARM). Another possible technique that can be used in modelling the decision criteria is the Block Replacement Model (BRM) ${ }^{39}$. However ARM has been chosen as the tool for modelling the decision criteria because BRM in most scenarios results in unnecessary replacement of equipment/components which makes the ARM technique more cost effective. ${ }^{40}$

Step 7. Determination of decision criteria weight: The weights of the decision criteria are evaluated using the compromise weighting technique which combines the AHP method with the statistical variance method.

Step 8 and Step 9. Ranking of scheduled replacement interval alternatives: The scheduled replacement interval alternatives are ranked using TOPSIS and the alternative with the highest TOPSIS performance index is chosen. 


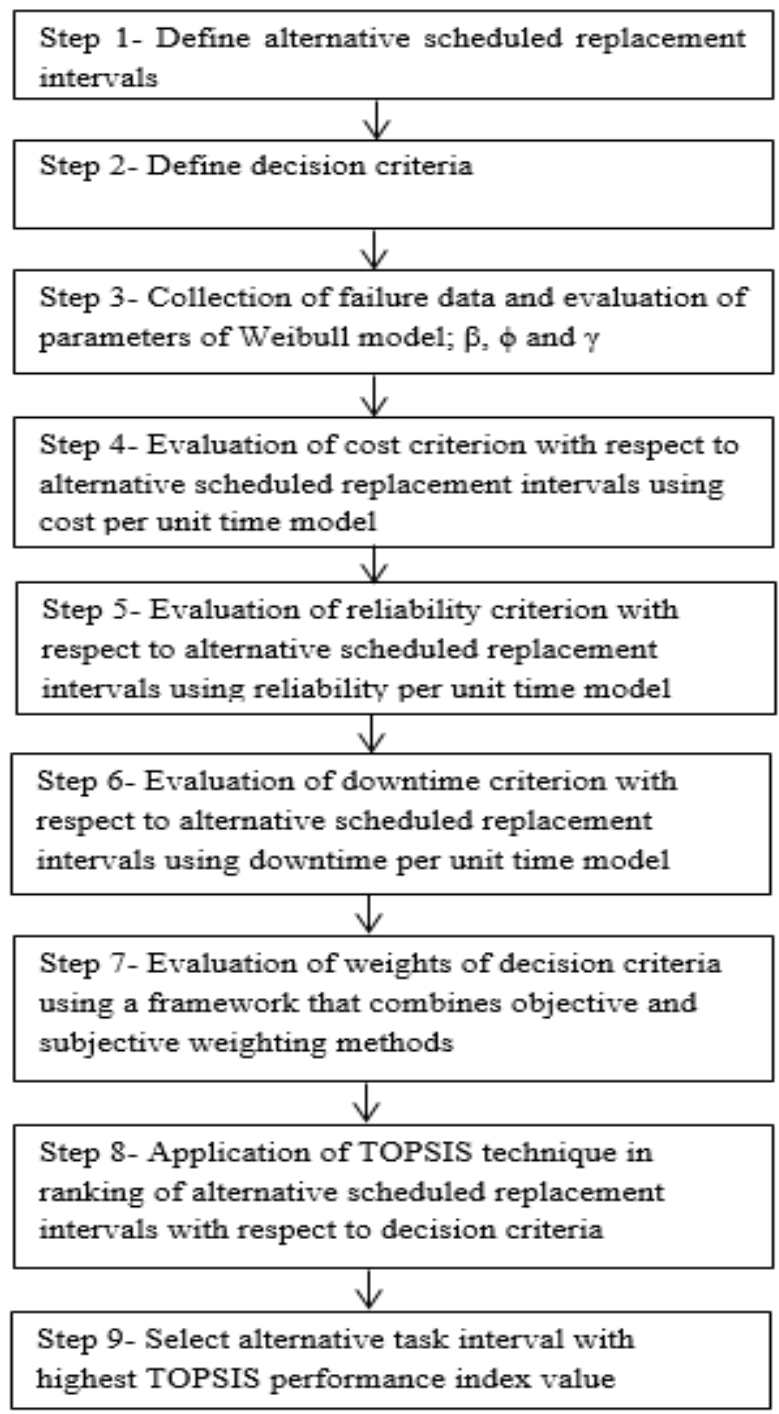

Figure 1 Flowchart of the methodology

\section{Case study: Marine diesel engine}

As part of ongoing research, risk assessment was performed on the marine diesel engine and the most critical components of the system were identified. For the basic engine which is one of the systems of the marine diesel engine, components such as the connecting rod, piston and turbocharger were identified as critical. ${ }^{34}$ Scheduled replacement was identified as the optimum maintenance strategy for mitigating critical failure modes of the connecting rod. ${ }^{41}$ Having determined the risk level and the type of maintenance strategy for mitigating failure, there is the need to determine the optimum interval for carrying out the maintenance task. On this basis, the connecting rod was used in demonstrating the applicability of the proposed scheduled replacement interval determination model. 


\subsection{Data collection}

When applying a life-time distribution such as the Weibull distribution or exponential distribution in curve fitting individual units' failure data or group failure data, reasonable accuracy can be obtained with only four or five data points. ${ }^{42}$ Rausand and Vatn ${ }^{43}$ reported that lack of reliability data will always be a challenge because of the difficulty in accessing operational data with adequate quality and because transforming operational data into reliability data is problematic. The authors further postulated that in spite of these challenges, useful maintenance decisions can still be made from the little or no data situation as there are other sources of data such as experts' opinions and reliability databanks available. In response to the challenges of obtaining failure data from the shipping industry, in this research values for Weibull parameters $\beta$ and $\emptyset$ for some of the components of the marine diesel engine were obtained from the work of Perakis and Inözü ${ }^{44}$ and they are presented in table 4 . The Weibull parameters are the key data required for the implementation of this methodology. However if time to failure data were to be available, the data could have been used as input into Eq. 1-8 to obtain Weibull parameters $\beta$ and $\varnothing$.

Table 4: Reliability data ${ }^{44}$

\begin{tabular}{lllllll}
\hline System & & Sub-system & Component & $\beta(\mathrm{hrs})$ & $\phi(\mathrm{hrs})$ & Environment \\
\hline $\begin{array}{l}\text { Marine } \\
\text { engine }\end{array}$ & diesel & Basic engine & Connecting rod & 3.432 & 31699 & Maritime \\
$\begin{array}{l}\text { Marine } \\
\text { engine }\end{array}$ & diesel & Basic engine & Cylinder head & 1.544 & 69764 & Maritime \\
$\begin{array}{l}\text { Marine } \\
\text { engine }\end{array}$ & diesel & Basic engine & Cylinder jacket & 2.195 & 74802 & Maritime \\
$\begin{array}{l}\text { Marine } \\
\text { engine }\end{array}$ & diesel & Basic engine & $\begin{array}{l}\text { Cylinder liner and } \\
\text { o-ring }\end{array}$ & 1.424 & 83769 & Maritime \\
$\begin{array}{l}\text { Marine } \\
\text { engine }\end{array}$ & diesel & Basic engine & Piston & 1.221 & 211070 & Maritime \\
$\begin{array}{l}\text { Marine } \\
\text { engine }\end{array}$ & diesel & Basic engine & Fuel cam & 0.710 & 60358 & Maritime \\
$\begin{array}{l}\text { Marine } \\
\text { engine }\end{array}$ & diesel & Basic engine & Turbocharger & 1.520 & 31756 & Maritime \\
\hline
\end{tabular}

Given the values of the Weibull parameters, the next step is to obtain the cost parameters; $C_{a}$, $C_{b}, T_{a}$ and $T_{b}$. However because cost data was also not available, values used by previous researchers were used which were in the form of ratios. For example Wong and Jefferis ${ }^{45}$ used a cost ratio of 1 to 5 ( $\$ 5000$ assumed as the replacement cost when performed under preventive 
mode and $\$ 25000$ assumed as the replacement cost when performed under failure mode) as the cost of preventive replacement to the cost of failure replacement. Furthermore Mobley ${ }^{6}$ stated that the cost of maintenance implemented under reactive mode is generally about three times the cost if executed in preventative mode. In this research a cost ratio of 1 to 4 was assumed as the cost of preventive replacement to the cost failure replacement. Also since the downtime as result of failure replacement is usually higher than that resulting from preventative replacement it was considered appropriate that a ratio of 1 to 5 was assumed as the ratio of downtime for preventive replacement to downtime for failure replacement.

The connecting rod parameters which were used as input data in the reliability function, cost function and downtime function were; $\beta=3.432$ and $\varnothing=31699, C_{a}=£ 8000, C_{b}=£ 2000, T_{a}=$ 3 and $T_{b}=15$.

\subsection{Criteria function evaluation}

Having obtained the Weibull parameters $\beta$ and $\varnothing$ and cost parameters; $C_{a}, C_{b}, T_{a}$ and $T_{b}$, the next step was to evaluate $\mathrm{R}, \mathrm{C}$ and $\mathrm{D}$ for all possible alternative replacement intervals which may then be used to form a decision table or matrix. In deciding on the possible scheduled replacement time interval alternatives, reference was made to literature ${ }^{44}$ in consultation with an expert who holds a $\mathrm{PhD}$ degree in marine engineering and has several years of experience in ship maintenance. The possible scheduled replacement time intervals arrived at are A1-A30 as $5000 \mathrm{hrs}$ to $34000 \mathrm{hrs}$ in steps of $1000 \mathrm{hrs}$. The evaluation of R, C and D was carried out using Eq. 10, 12 and 13 respectively and the results obtained are presented in Figures 2 to 4 . 


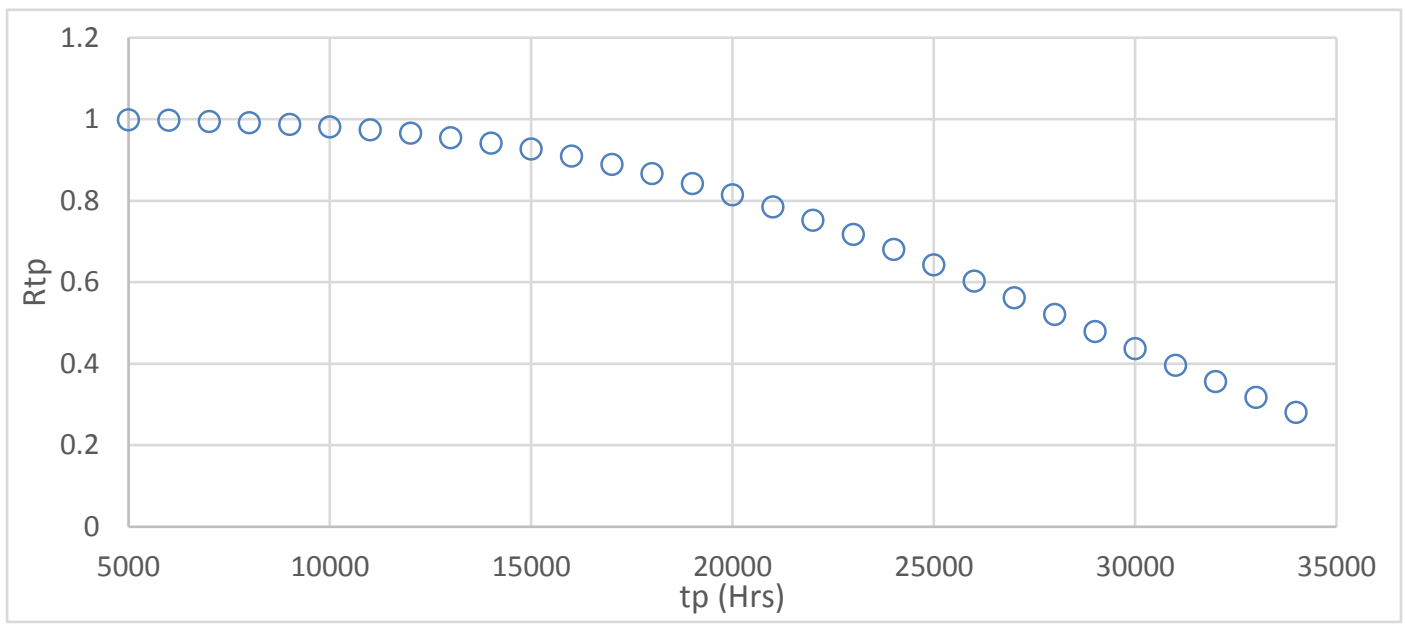

Figure 2: Reliability function against scheduled replacement interval $t_{p}$

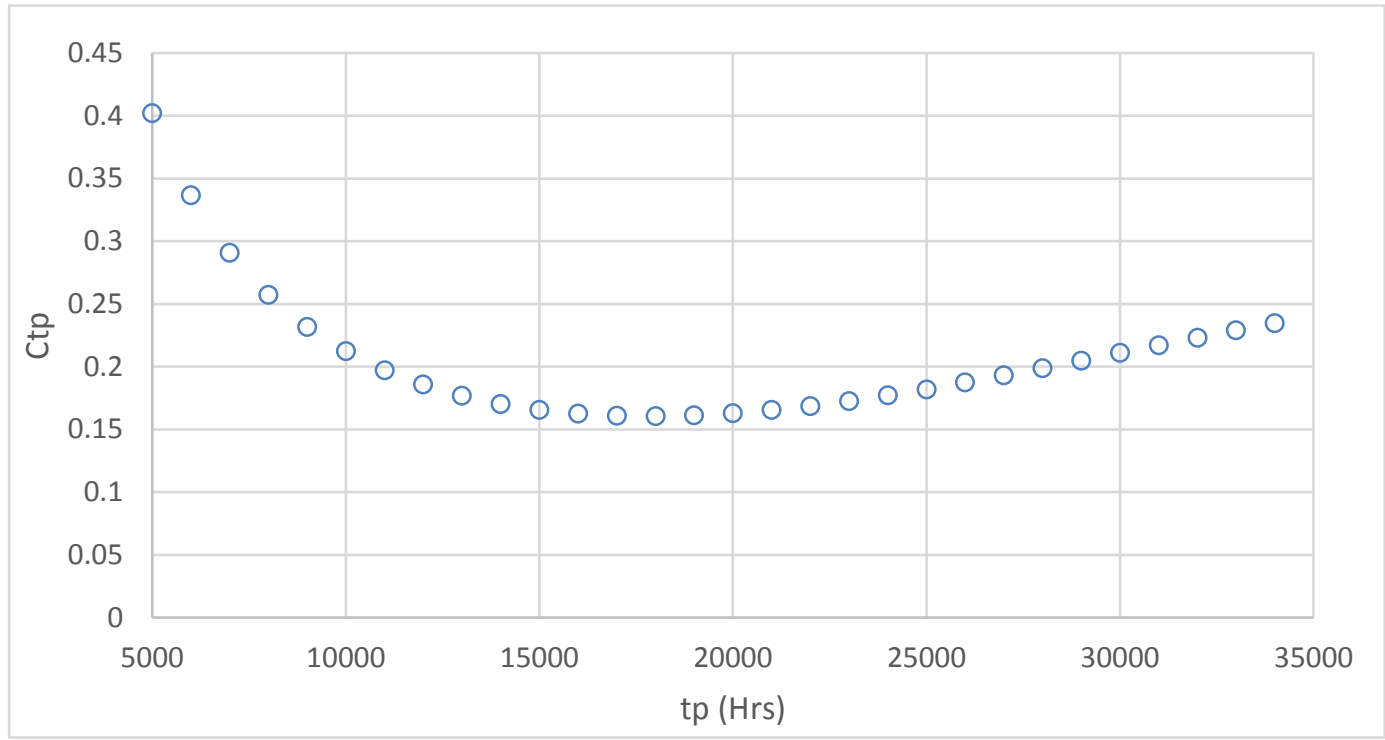

Figure 3: Cost function against scheduled replacement interval $t_{p}$ 


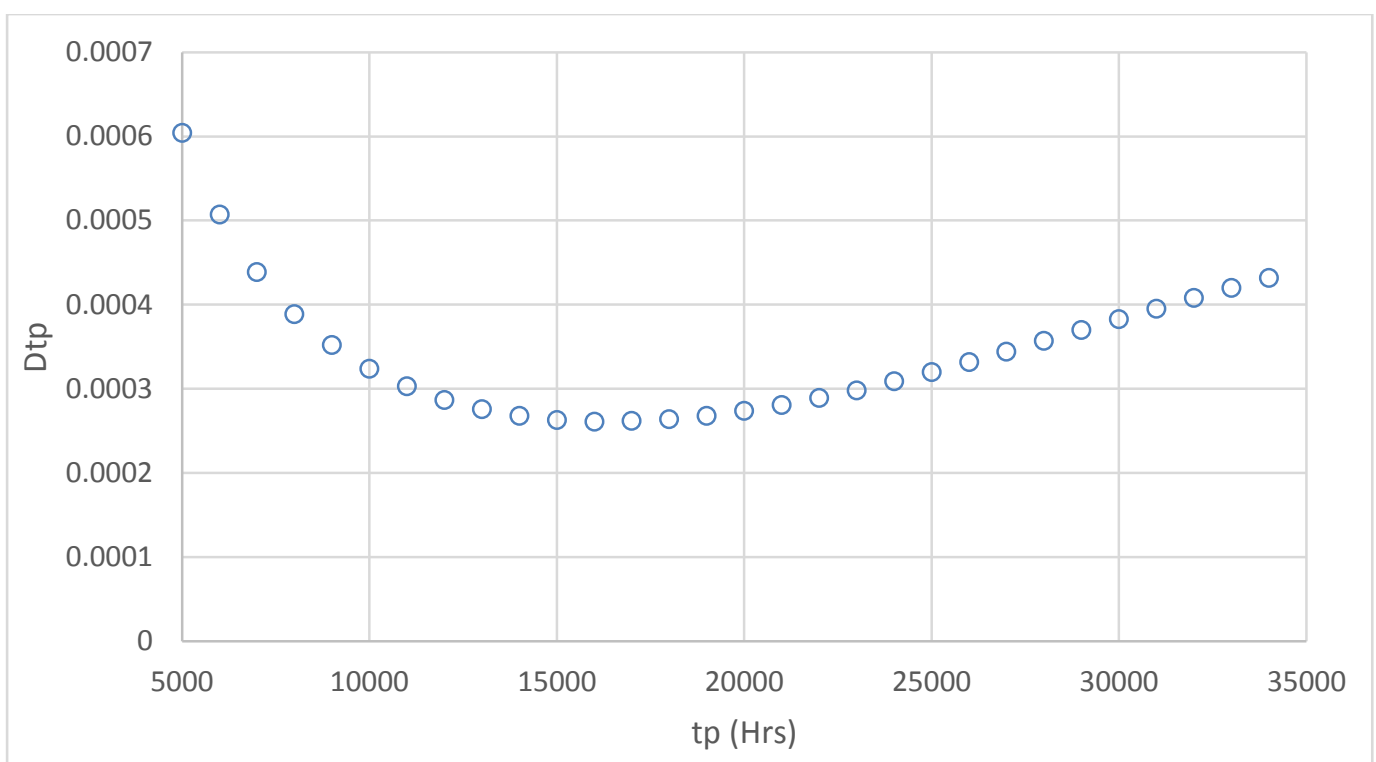

Figure 4: Downtime function against scheduled replacement interval

From the results in Figures 2, 3 and 4 it is obvious that the three decision criteria are in conflict with one another making it difficult to select the optimum scheduled replacement interval. For example: the maintenance practitioner would prefer to maintain the plant with the highest possible reliability and, as such, for the reliability function in Figure 2 the optimum scheduled replacement interval is 5000hrs; however considering the cost function in Figure 3, the optimum replacement interval will occur at the least possible cost and in this case the preferred maintenance interval is $18,000 \mathrm{hrs}$ and finally for the downtime function in Figure 4 the maintenance practitioner would prefer to operate the plant with the least possible plant downtime and from this analysis the optimum solution would be to carry out replacement at an interval of $16,000 \mathrm{hrs}$. From this description it is obvious the optimum solution need be less or equal $18,000 \mathrm{hrs}$ and need be greater than 5,000hrs. In some instances the gap might be larger or greater numbers of alternatives which might be very confusing for the decision makers. Hence previous authors suggested the use of a PROMETHEE based method for solving the problem. However for simplicity a more straightforward approach i.e. the use of the TOPSIS method is proposed in this research in selecting the most appropriate preventive replacement alternative interval. In the TOPSIS technique the first step is to form the decision matrix which is achieved from the results generated for $R, C$ and $D$ for scheduled replacement intervals A1 to $\mathrm{A} 30$ as presented in Table 5 . 
Table 5: decision matrix for connecting rod

\begin{tabular}{|c|c|c|c|c|}
\hline Replacement interval (tp) & $\operatorname{tp}(\mathrm{hrs})$ & Rtp & Ctp & Dtp \\
\hline A1 & 5000 & 0.998234 & 0.402036 & 0.000604 \\
\hline $\mathrm{A} 2$ & 6000 & 0.996702 & 0.336712 & 0.000507 \\
\hline A3 & 7000 & 0.994408 & 0.290747 & 0.000439 \\
\hline A4 & 8000 & 0.991171 & 0.257035 & 0.000389 \\
\hline A5 & 9000 & 0.986803 & 0.231631 & 0.000352 \\
\hline A6 & 10000 & 0.981108 & 0.212175 & 0.000324 \\
\hline A7 & 11000 & 0.973894 & 0.197167 & 0.000303 \\
\hline A8 & 12000 & 0.964970 & 0.185607 & 0.000287 \\
\hline A9 & 13000 & 0.954153 & 0.176806 & 0.000276 \\
\hline A10 & 14000 & 0.941272 & 0.170267 & 0.000268 \\
\hline A11 & 15000 & 0.926174 & 0.165626 & 0.000263 \\
\hline A12 & 16000 & 0.908729 & 0.162604 & 0.000261 \\
\hline A13 & 17000 & 0.888834 & 0.160983 & 0.000262 \\
\hline A14 & 18000 & 0.866420 & 0.160589 & 0.000264 \\
\hline A 15 & 19000 & 0.841456 & 0.161276 & 0.000268 \\
\hline A16 & 20000 & 0.813957 & 0.162918 & 0.000274 \\
\hline A17 & 21000 & 0.783981 & 0.165407 & 0.000281 \\
\hline A18 & 22000 & 0.751638 & 0.168643 & 0.000289 \\
\hline A19 & 23000 & 0.717090 & 0.172532 & 0.000298 \\
\hline A 20 & 24000 & 0.680550 & 0.176986 & 0.000309 \\
\hline A 21 & 25000 & 0.642279 & 0.181920 & 0.000320 \\
\hline A22 & 26000 & 0.602586 & 0.187251 & 0.000332 \\
\hline A23 & 27000 & 0.561822 & 0.192896 & 0.000344 \\
\hline A24 & 28000 & 0.520369 & 0.198773 & 0.000357 \\
\hline A 25 & 29000 & 0.478633 & 0.204805 & 0.000370 \\
\hline A26 & 30000 & 0.437038 & 0.210912 & 0.000383 \\
\hline A 27 & 31000 & 0.396005 & 0.217019 & 0.000395 \\
\hline A28 & 32000 & 0.355949 & 0.223053 & 0.000408 \\
\hline A29 & 33000 & 0.317263 & 0.228948 & 0.000420 \\
\hline A30 & 34000 & 0.280303 & 0.234641 & 0.000432 \\
\hline
\end{tabular}

\subsection{Criteria weights determination}

After the formation of the decision matrix, the next step was to use the MCDM tool in ranking of the alternative maintenance intervals. However prior to the use of the MCDM tool, the weight of each decision criterion had to be determined. As previously explained, a combination of AHP and the variance weighting method was used in this research. Firstly the decision 
criteria weights were estimated with the AHP method by applying Eq. 14-19 on the pairwise comparison judgement obtained from three experts. Next the variance technique was utilised to determine criteria weights. Applying the variance method the decision matrix in Table 5 was normalised using Eq. 20. The decision criteria (R, C and D) weights were then estimated using Eq. (21) and (22) to the normalised decision matrix. Finally, the compromise weighting method was utilised by applying Eq. 23 on the results obtained from AHP and variance methods. The results of weights of R, C and D obtained from the AHP and variance techniques together with compromise weighting technique are presented in Table 6.

Table 6: Combined weight technique comparison with others

\begin{tabular}{llll}
\hline & $\mathrm{R}$ & $\mathrm{C}$ & $\mathrm{D}$ \\
\hline AHP & 0.6000 & 0.2000 & 0.2000 \\
variance & 0.4362 & 0.3132 & 0.2506 \\
Compromise & 0.6989 & 0.1673 & 0.1338 \\
\hline
\end{tabular}

\subsection{Scheduled replacement intervals ranking: TOPSIS application}

The evaluated compromise weights of $\mathrm{R}, \mathrm{C}$ and $\mathrm{D}$ together with data in the decision matrix in Table 5 were then used as input data for the TOPSIS analysis. The first step in the TOPSIS analysis was the normalisation of the decision matrix in Table 5 using Eq. 20. The weighted normalised matrix was then obtained by multiplying the normalised decision matrix by the decision criteria weights. Applying Eq. 25 and 26, positive and negative ideal solutions were obtained and the results are presented in Table 8. Using Eq. 27 and 28 the separation of each of the alternative replacement intervals from the positive and negative ideal solutions were then evaluated. Finally, the relative closeness of each alternative replacement interval to the positive ideal solution was evaluated using Eq. 29 and the results together with their corresponding rankings are presented in Figure 5.

Table 8: Positive and negative ideal solution

\begin{tabular}{lcc}
\hline Criteria & Negative ideal & Positive ideal \\
\hline Reliability & 0.2083 & 0.9982 \\
Cost & 0.40108 & 0.1605 \\
Downtime & 0.0006 & 0.00026 \\
\hline
\end{tabular}




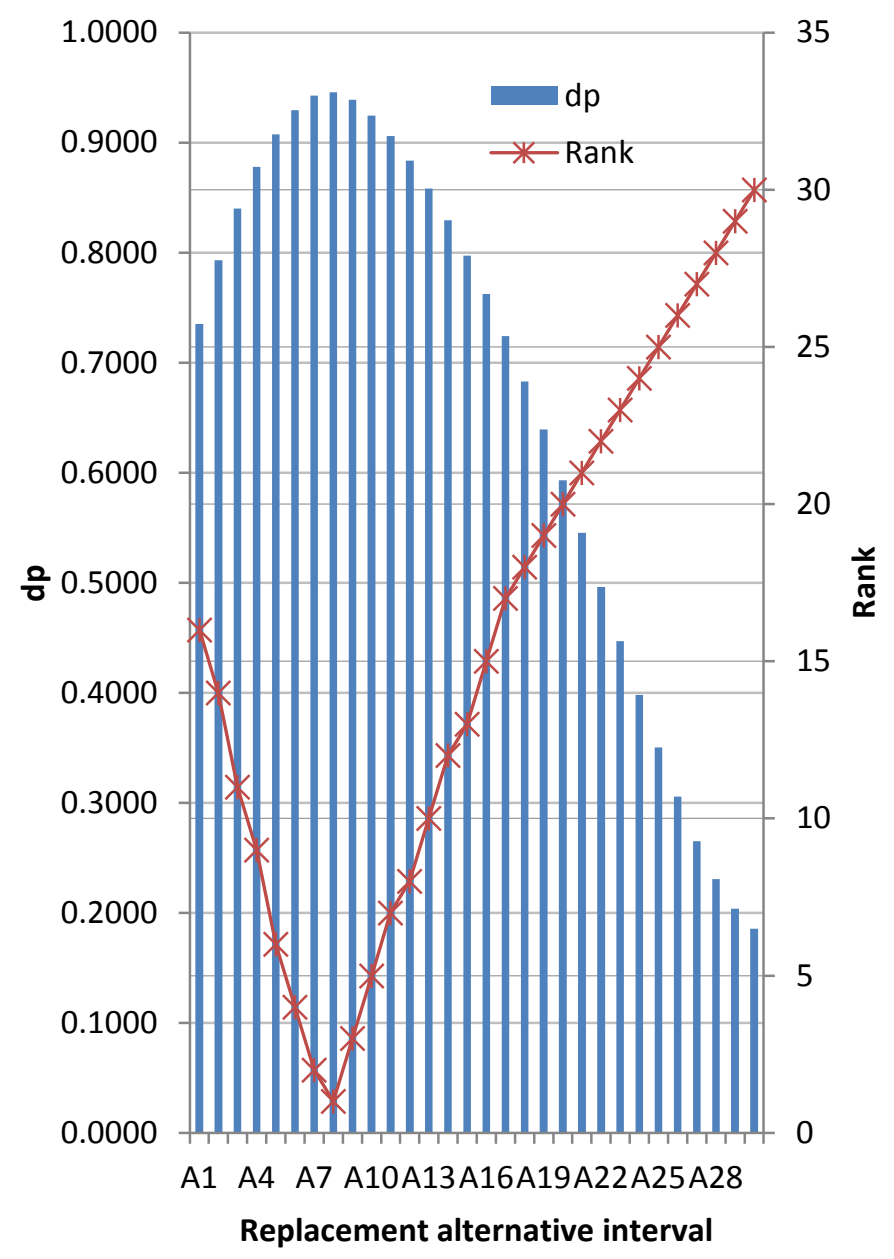

Figure 5: Relative closeness to positive ideal and ranking

From Figure 5 it is obvious that the optimum solution is A8 (12000hrs) having the highest TOPSIS performance index of 0.9452 . However the optimum interval can vary from system to system depending on the input parameters applied to the model which is controlled by the system age, system failure distribution (such as Weibull, normal and exponential distribution) demand, prevailing cost factor, maintenance practitioner opinion and the environment of the operation of the system. A sensitivity study was then carried out to see how the various factors affect the optimum choice. 


\subsection{Impact of input parameters variations on the overall ranking replacement interval alternatives using TOPSIS}

To determine robustness of the TOPSIS technique in the ranking of replacement interval alternatives the impact of the variations of input parameters on the overall ranking of the replacement alternative intervals was performed. The TOPSIS performance index for all replacement interval alternatives was generated as the individual input parameters were varied and based on the TOPSIS performance index obtained in all the scenario, replacement alternative intervals were ranked.

\subsubsection{Impact of $\beta$ variations on the overall ranking of replacement interval alternative}

Firstly the impact of the variation of $\beta$ on the overall ranking of the alternative replacement intervals was considered. The TOPSIS performance index was obtained for all replacement interval alternatives as input parameter $\beta$ was increased and decreased by $5 \%, 10 \%, 15 \%$ and $20 \%$. The result obtained is presented in Figure 6 a \& b. Note Figure $6 \mathrm{~b}$ is a section of Figure $6 a$ and it's presented to clearly shown how replacement alternative intervals vary with increase or decrease of parameter $\beta$. 


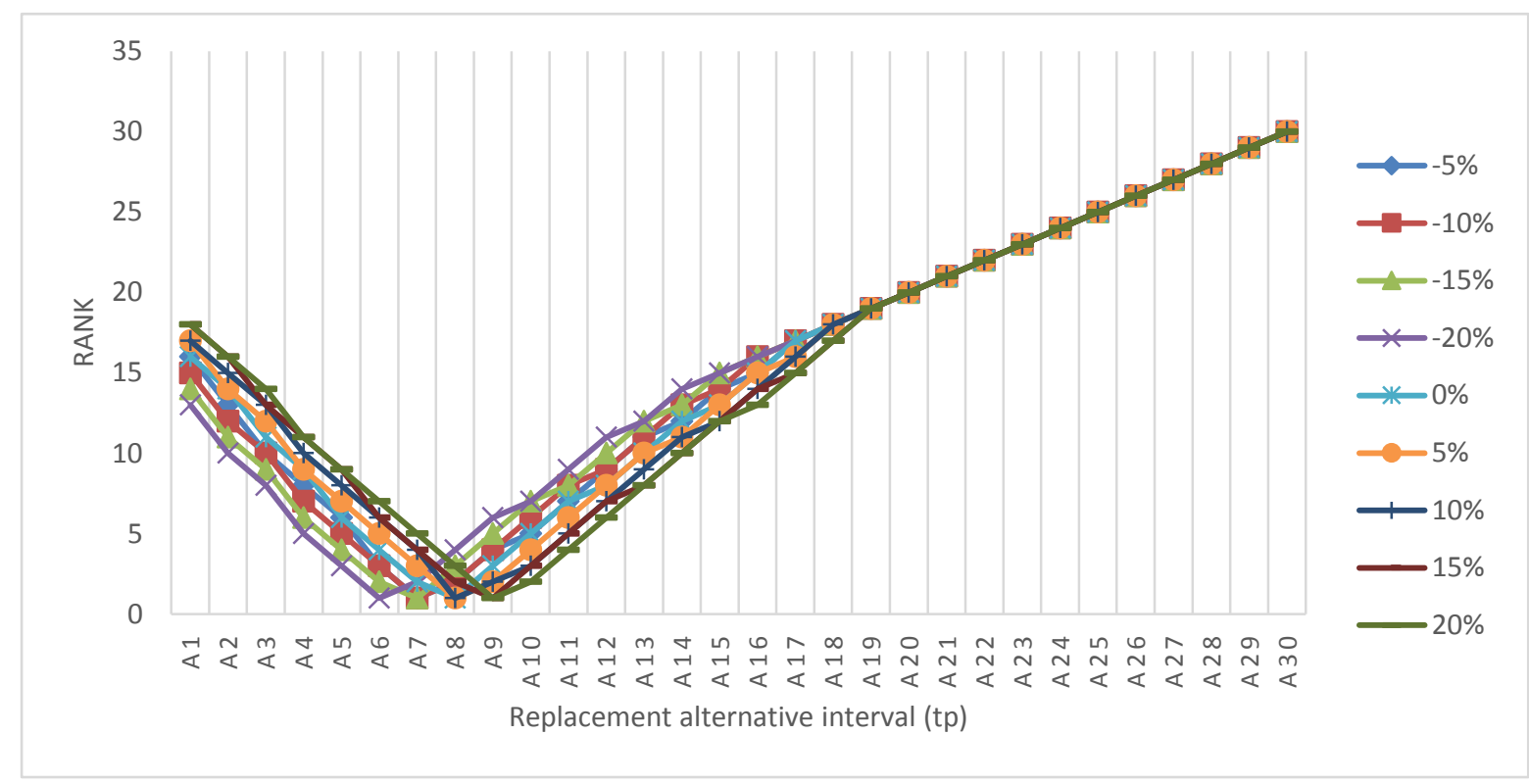

(a)

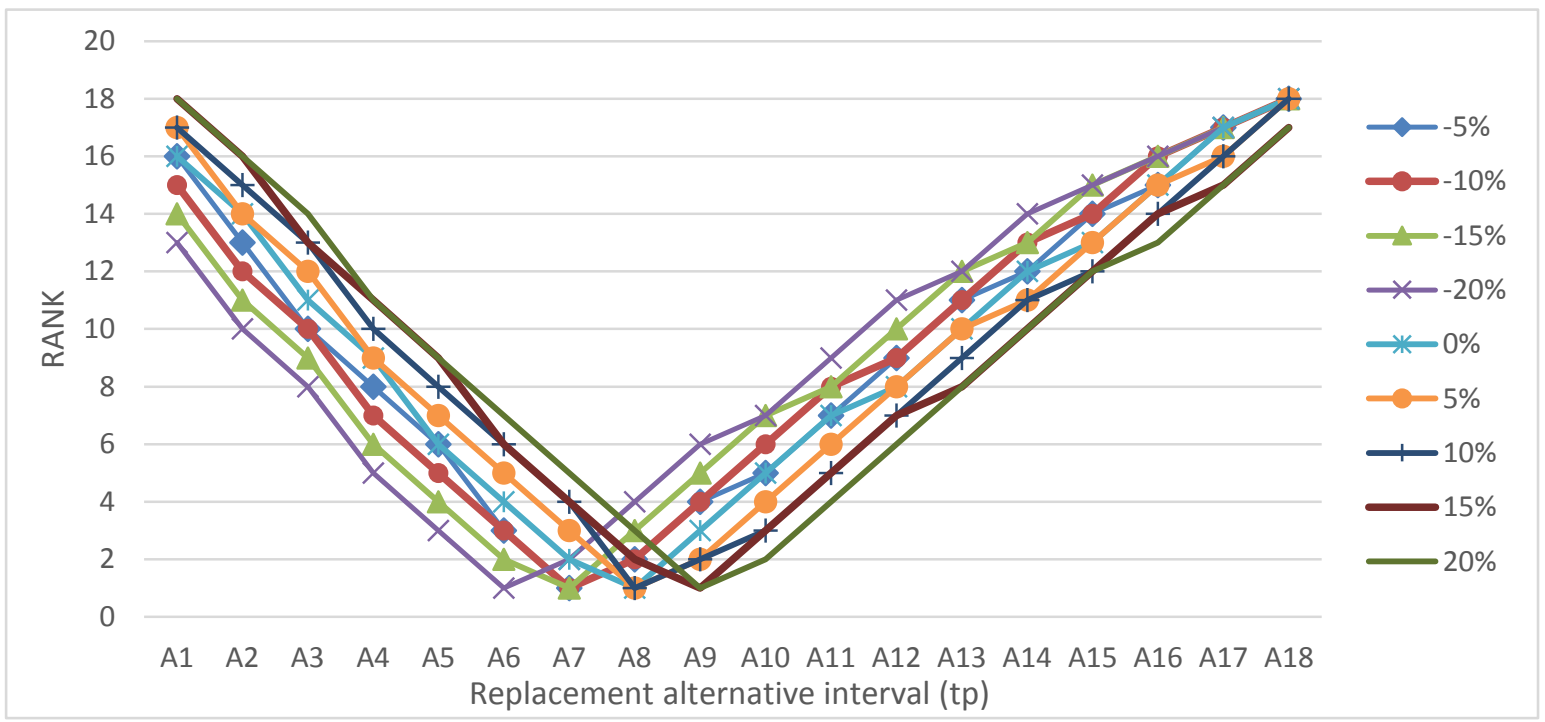

(b)

Figure 6: Ranking of sensitivity analysis of $\beta$ (a) for the full range of time intervals (b) for intervals A1-A18

From Figure $6 \mathrm{~b}$ it can be seen that the optimal replacement interval for the original value of $\beta$ $(0 \%)$ was A8 $(12,000 \mathrm{hrs})$ having rank of 1 . However as the value of $\beta$ was increased by $10 \%$ the optimal replacement interval remained unchanged. It was not until $\beta$ was increased by $15 \%$ and $20 \%$ that the optimal interval became A9 $(13,000 \mathrm{hrs})$. On the other hand, as the value of $\beta$ was decreased by $5 \%$ the optimal replacement interval changed to A7 $(11,000 \mathrm{hrs})$ and it further changed to A6 (10,000hrs) when the value of $\beta$ was decreased by $20 \%$. To summarise, the 
higher the value of $\beta$ the higher the replacement interval and the lower the value of $\beta$ the lower the replacement interval. An additional conclusion is that in all the scenarios, whether increasing or decreasing the value of $\beta$, the optimal replacement interval varied by a relatively small amount as the change was over the range A6 - A9.

\subsubsection{Impact of $\phi$ variations on the overall ranking replacement interval alternatives}

The impact of $\emptyset$ on the overall ranking of alternative replacement intervals was performed by decreasing and increasing the values of $\varnothing$ by $5 \%, 10 \%, 15 \%$ and $20 \%$ and using the results obtained in each scenario as input to the TOPSIS methodology. On the basis of the TOPSIS performance indices, the replacement alternative intervals were ranked and the results are presented in Figure 7.

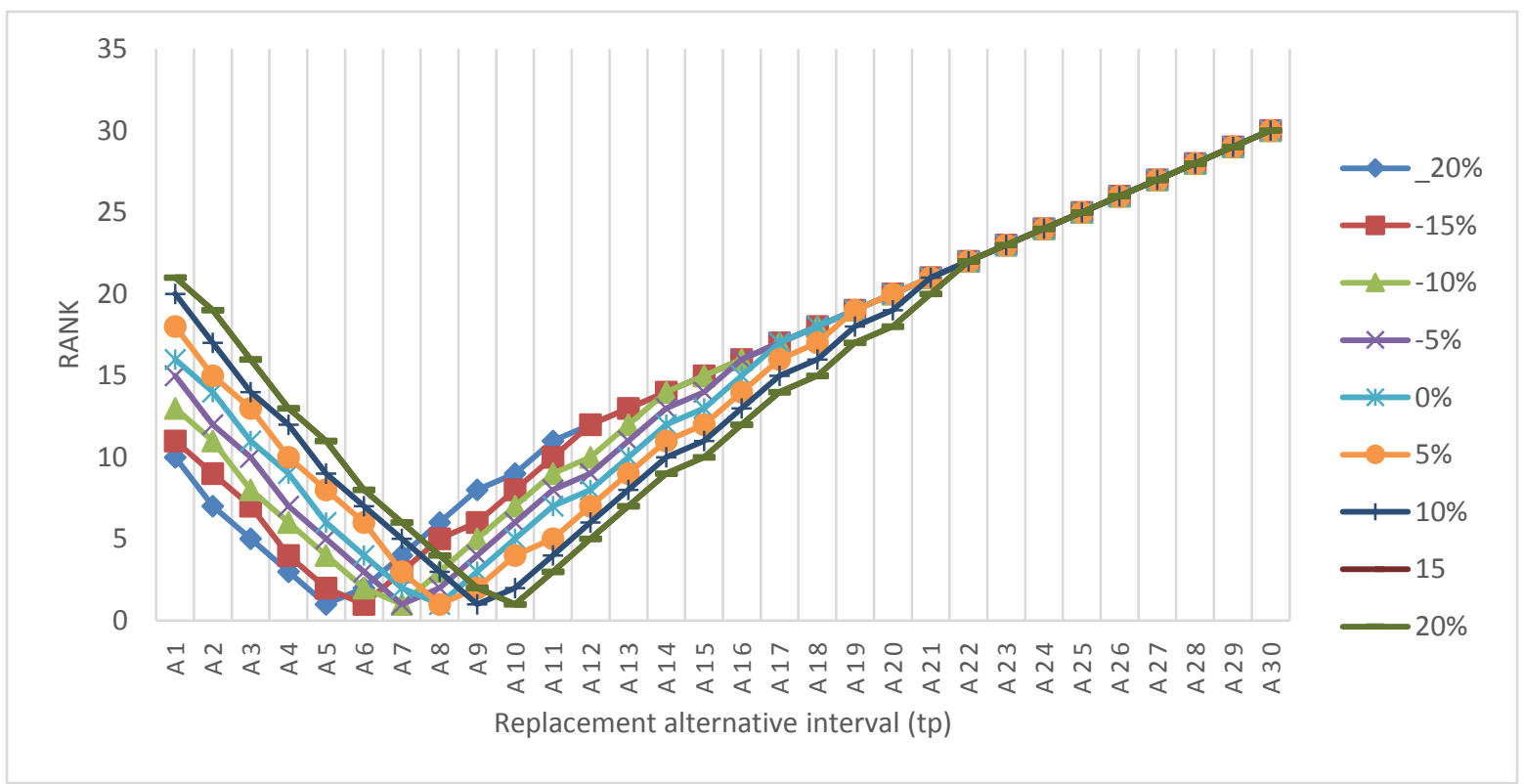

Figure 7: Ranking of sensitivity analysis of $\emptyset$

From Figure 7, it can be seen that the sensitivity analysis results obtained for $\emptyset$ are very similar to the results generated for $\beta$ since as the value of $\varnothing$ increased the replacement interval increases and as the value decreases the replacement interval decreased just as in the case of $\beta$. However, the corresponding changes in the replacement interval to the changes in $\varnothing$ are larger than the response to the changes in $\beta$. In other words, the ranking model is more sensitive to changes in $\varnothing$ than $\beta$. 
A sensitivity analysis was performed on cost ratio to determine the effect that changes of the ratio of $C_{a}$ to $C_{b}$ would have on the overall ranking of replacement interval alternatives. The ratio of $C_{a}$ to $C_{b}$ ranging from 2 to 8 was applied in carrying out the investigation. The ranking of replacement alternative intervals obtained based on the TOPSIS performance index is shown in Figure $8 \mathrm{a} \& \mathrm{~b}$. Note Figure $8 \mathrm{~b}$ is a section of Figure $8 \mathrm{a}$ and it's presented to clearly show how replacement interval alternatives vary with increased or decreased cost ratio.

From Figure $17 \mathrm{a}$ it can be seen that as the ratio of $C_{a}$ to $C_{b}$ increased up to $5 \%$ there was a reduction in the replacement interval. Increased beyond $5 \%$ resulted in no further change across the range of scenarios i.e. the ratio of $C_{a}$ to $C_{b}$ ranging from 2 to 8 , only three replacement interval choices were obtained (A9, the optimal replacement interval obtained for $C_{a}: C_{b}=2$, the A8 optimal replacement interval obtained for $C_{a}: C_{b}=3$ to 4 and $\mathrm{A} 7$ the optimal replacement interval obtained for $C_{a}: C_{b}=5$ to 8 ). It can be concluded that as the ratio increases, the replacement interval decreases up to a point and then remains constant. When compared to $\beta$ and $\varnothing$ the cost ratio has a smaller impact on the ranking of replacement interval alternatives. 


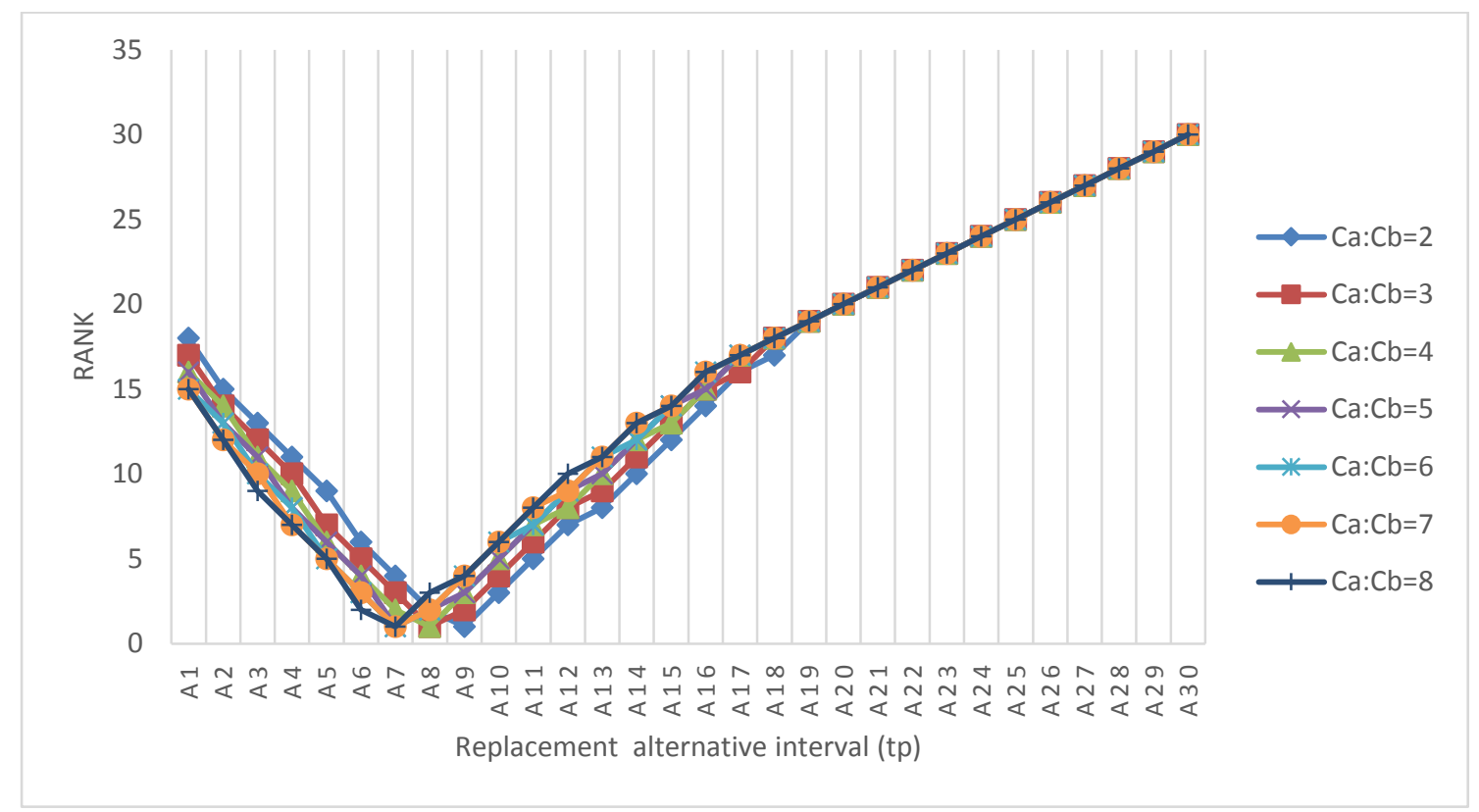

(a)

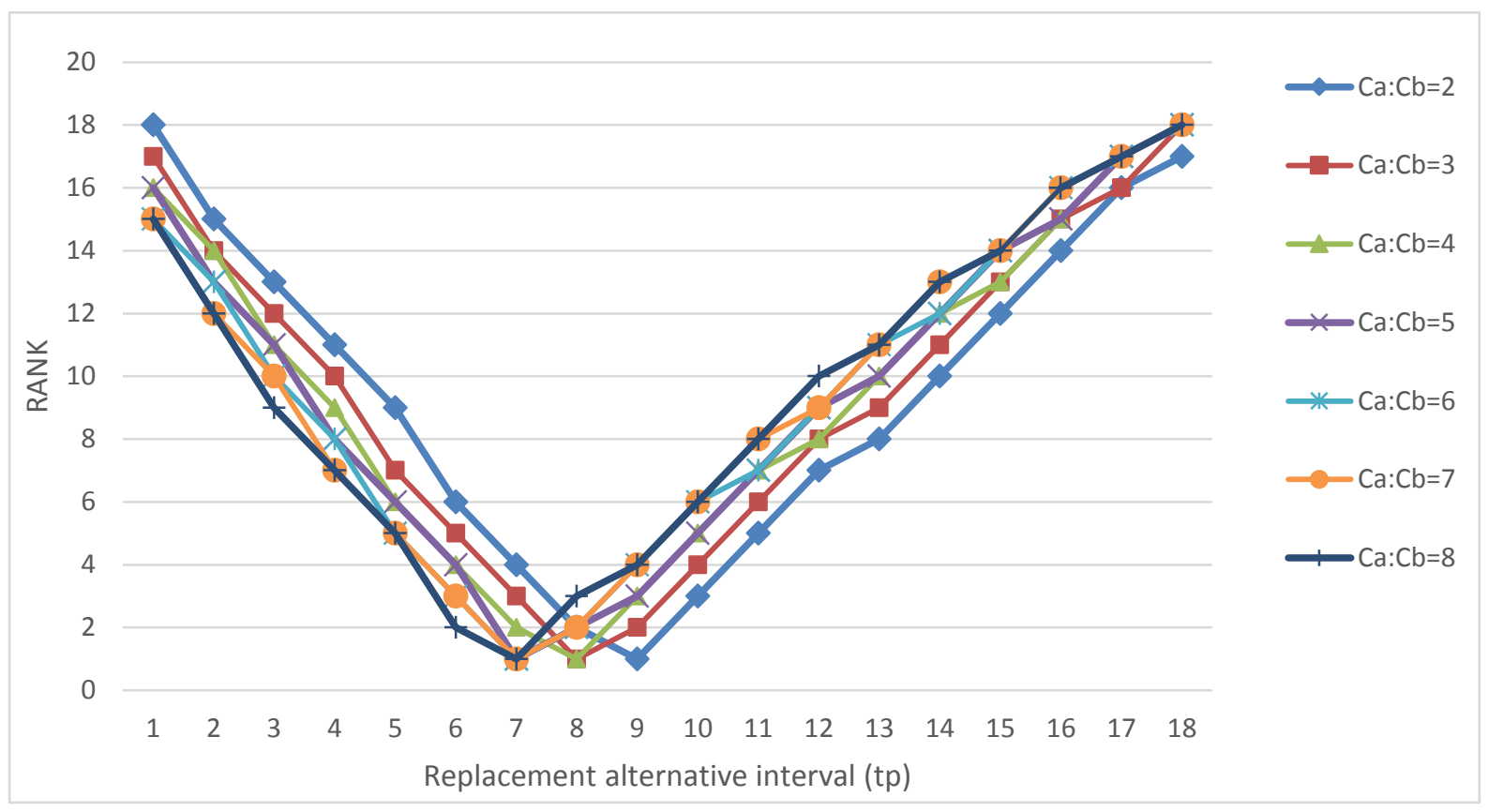

(b)

Figure 8: Ranking of sensitivity analysis of cost ratio (a) for the full range of replacement alternative intervals (b) for intervals A1-A18 
In order to determine the impact that variation of the ratio $T_{b}$ to $T_{a}$ would have on the overall ranking of replacement interval alternatives, the ratio of $\mathrm{Tb}$ to Ta was varied from 2 to 9 . The performance index for the replacement interval alternatives in the nine scenarios were ranked and the results are presented in Figure 9. It is obvious from the figure that the optimal replacement interval for the scenarios remained unchanged with the exception of the first scenario ( $T_{b}$ to $T_{a}$ equal to 2 ). When compared to the other input parameters the $T_{b}$ to $T_{a}$ ratio has less impact on the overall ranking of replacement interval.

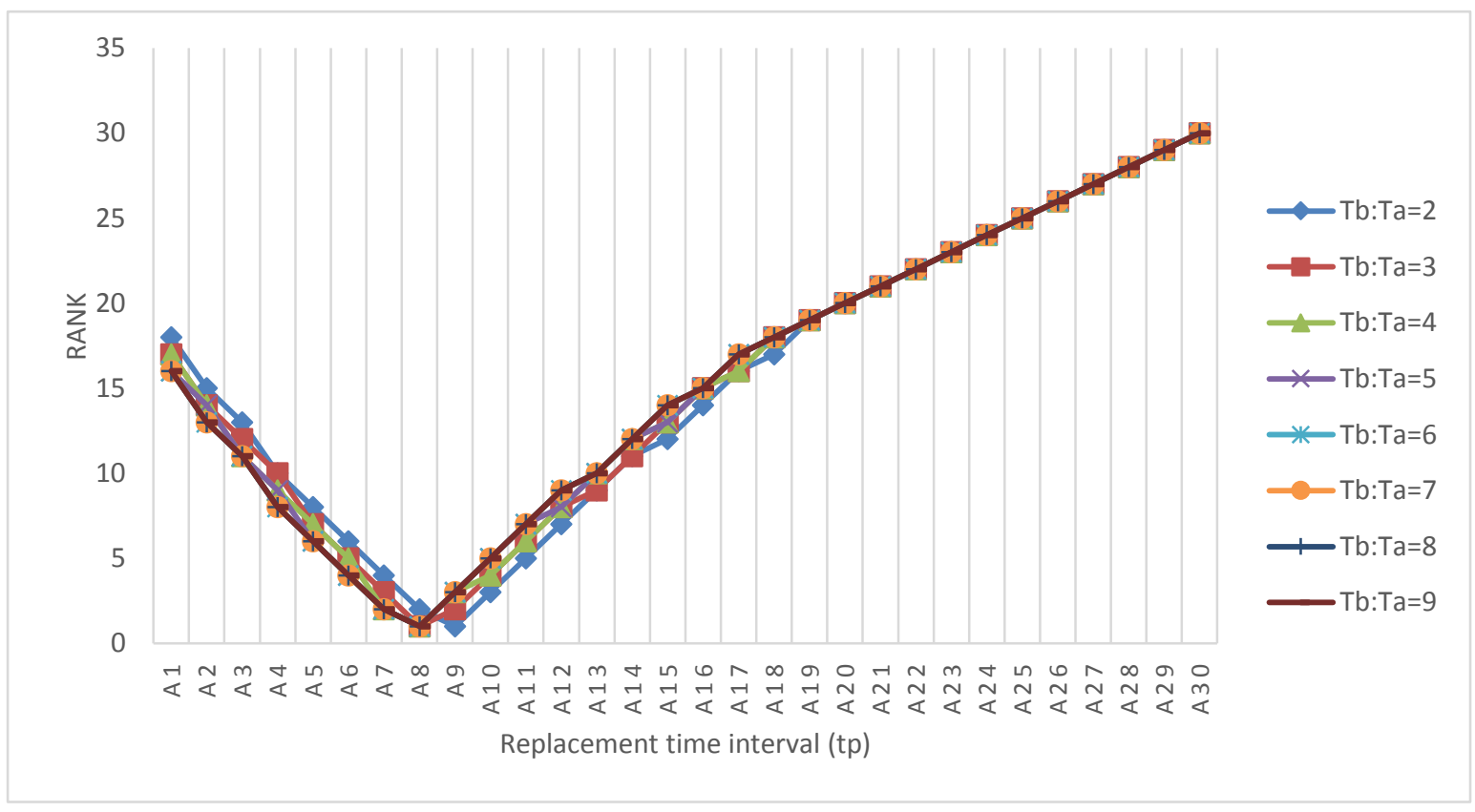

Figure 9: Ranking of sensitivity analysis of ratio of $\mathrm{T}_{\mathrm{b}}$ to $\mathrm{T}_{\mathrm{a}}$

\subsection{Comparison of proposed ranking method with existing approach}

In order to validate the proposed TOPSIS technique as a tool for ranking scheduled replacement interval alternatives it was compared with the existing PROMETHE method previously used for land based system using the case study of the marine diesel engine. The compromise weighting was not used by previous authors in determining criteria weights for the PROMETHEE method but for unbiased comparison the compromise weighting technique was used to determine weights of criteria for both TOPSIS and PROMETHEE. From the comparative analysis the same optimum solution of A8 (12000hrs) was produced by both methods using the original data (without parameter data variation) of the marine diesel engine. Furthermore, when data variation (sensitivity analysis) was performed, both methods 
responded to parameter variation in a similar manner and in all the scenarios of parameter variation, the same optimum solution was obtained by both methods. Although both techniques yielded the same optimum solution for the marine based system, the TOPSIS methodology is more suitable for the marine system because of its ease of implementation due to requiring less computational effort in the decision making process irrespective of the number of decision criteria unlike PROMETHEE methodology in which computational effort required for implementation increases as the number of decision criteria increases. Furthermore, the TOPSIS methodology does not require the maintenance practitioner or analyst to determine preference functions for each of the decision criteria whereas the PROMETHEE method creates this additional burden for maintenance practitioners which may discourage them from using it in the marine environment that is harsh and isolated.

\section{Conclusion}

For safe and reliable operation of marine machinery systems at reasonable cost there needs to be in place an efficient maintenance system. However in making maintenance decisions, different parties are involved and the decisions are usually based on certain criteria which are always in conflict with one another. Multi-criteria decision making techniques are usually suitable for resolving such conflicts. In this research, decision criteria of reliability, cost and downtime were considered as the basis for selecting the optimum preventive replacement interval for marine machinery systems. Since the three decision models are in conflict with one another, the outputs were aggregated with the aid of MCDM techniques. In order to demonstrate the applicability of the methodology, failure data obtained from secondary sources and estimated cost data for the connecting rod of a marine diesel engine were used as input data. The result of the investigation reveals the following:

(1) For the data considered using the TOPSIS methodology, the optimum replacement interval for performing maintenance tasks on the connecting rod of the marine diesel engine is $12,000 \mathrm{hrs}$. However this is not fixed as the interval could vary depending on the operating environment of the system, the age of the system, cost of replacement at breakdown, cost of preventive replacement and type of failure distribution.

(2) $\varnothing$ has the greatest influence on the overall ranking of replacement interval. On the other hand, the ratio of $T_{b}$ to $T_{a}$ has the least impact on the overall ranking of replacement intervals as increasing or decreasing the ratio does not significantly change the replacement interval of the system.

(3) Increasing the values of parameters such as $\varnothing$ and $\beta$ will result in a corresponding increase in the replacement interval and reducing the value will result in a reduction in the replacement interval. 
(4) Comparing TOPSIS used as a tool for ranking alternatives with the PROMETHEE method used by previous authors, results show that both techniques reacted to parameter variations in almost completely the same way and in all the scenarios of parameter variation the same optimum solutions were obtained for the marine diesel engine equipment item considered.

The approach in this research has an advantage over the PROMETHEE techniques applied by some authors for land-based systems as the proposed methodology is implemented with ease irrespective of the number of decision criteria used in the decision making process whereas in applying the PROMETHEE method the evaluation process becomes more and more complicated as decision criteria increase. Also the proposed technique does not require maintenance practitioners or decision makers to determine preference functions for all decision criteria chosen on the basis of which scheduled replacement interval alternatives are ranked. Furthermore, the proposed approach is more flexible in terms of criteria weight determination as it make it possible for the maintenance practitioners to either use a subjective approach or an objective approach or a combination of the two. Although the PROMETHEE-based method was applied for land-based systems in the literature, it could also be applied to marine systems. Similarly, the TOPSIS-based method proposed in this paper for marine systems can equally well be applied to land-based systems as there is actually no distinction in its implementation for either land-based or marine systems, however the benefits stated above will make the proposed technique attractive to maintenance practitioners in the marine industry who work in a harsh and isolated environment.

\section{Acknowledgements}

The authors would like to thank the Federal University of Petroleum Resources, Effurun, Nigeria for funding this research through the TETFUND academic staff training intervention fund. They would also like to thank the School of Marine Science and Technology, Newcastle University, United Kingdom for providing the enabling environment for conducting this research.

\section{References}

1 Wang J, Pillay A, Kwon YS, Wall AD and Loughran CG. An analysis of fishing vessel accidents. Accid Anal Prev 2005; 37: 1019-24.

2 Emovon I, Norman RA and Murphy AJ. Hybrid MCDM based methodology for selecting the optimum maintenance strategy for ship machinery systems. J Intell Manuf. Epub ahead of print September 2016. DOI: DOI 10.1007/s10845-015-1133-6 
3 Dhillon BS. Engineering maintenance: A modern approach. Florida: CRC press 2002.

4 Bahrami-G K, Price JWH and Mathew J. The constant-interval replacement model for preventive maintenance: A new perspective. Int J Qual Reliab Manage 2000; 17: 82238.

5 Duarte JAC, Craveiro JCTA and Trigo TP. Optimization of the preventive maintenance plan of a series components system. Int J Press Vessels and Pip 2006; 83: 244-248.

6 Mobley RK. Plant Engineers Handbook. Oxford: Butterworth-Heinemann, 2001.

7 Waeyenbergh G, Pintelon L. Maintenance concept development: A case study. Int J Prod Econ 2004; 89: 395-405.

8 Li JR, Khoo LP, Tor SB. Generation of possible multiple components disassembly sequence for maintenance using a disassembly constraint graph. Int J Prod Econ 2006; 102: 51-65.

9 Mishra RC, Pathak K. Maintenance engineering and management: PHI Learning Pvt. Ltd. 2012.

10 Goossens AJM, Basten RJI. Exploring maintenance policy selection using the Analytic Hierarchy Process; An application for naval ships. Reliab Eng Sys Saf 2015;142: 3141.

11 Aven T, Jensen U. Stochastic models in reliability: Springer 1999.

12 Huang J, Miller CR, Okogbaa OG. Optimal preventive-replacement intervals for the Weibull life distribution: solutions and applications. In: Proceedings of IEEE Reliability and Maintainability Symposium, Washington DC, United States, Jan 16-19, 1995, pp. 370-377.

13 Barlow R, Hunter L. Optimum preventive maintenance policies. Oper Res 1960; 8: 90100.

14 Cheng Y-H, Tsao H-L. Rolling stock maintenance strategy selection, spares parts' estimation, and replacements' interval calculation. Int J Prod Econ 2010;128:404-412.

15 Das AN, Acharya D. Age replacement of components during IFR delay time. Reliability, IEEE Trans Reliab. 2004;53:306-312.

16 Jiang R, Ji P, Tsang AHC. Preventive effect of optimal replacement policies. J Qual Maint Eng 2006;12:267-274.

17 Ahmad R, Kamaruddin S, Azid I, Almanar I. Maintenance management decision model for preventive maintenance strategy on production equipment. $J$ Ind Eng Int 2011;7(13):22-34.

18 Gopalaswamy V, Rice JA, Miller FG. Transit vehicle component maintenance policy via multiple criteria decision making methods. J Oper Res Soc 1993:37-50.

19 Chareonsuk C, Nagarur N, Tabucanon MT. A multicriteria approach to the selection of preventive maintenance intervals. Int J Prod Econ 1997;49:55-64. 
20 Cavalcante CAV, De Almeida AT. A multi-criteria decision-aiding model using PROMETHEE III for preventive maintenance planning under uncertain conditions. $J$ Qual Maint Eng 2007;13:385-97.

21 Cavalcante CAV, Ferreira RJP, de Almeida AT. A preventive maintenance decision model based on multicriteria method PROMETHEE II integrated with Bayesian approach. IMA J Manage Math 2010;21:333-348.

22 Macharis C, Springael J, De Brucker K, Verbeke A. PROMETHEE and AHP: The design of operational synergies in multicriteria analysis.: Strengthening PROMETHEE with ideas of AHP. Eur J Oper Res 2004;153:307-317.

23 Hwang CL, Yoon K. Multiple attribute decision making: Methods and applications. Newyork: Springer-Verlag 1981.

24 Krishnasamy L, Khan F, Haddara M. Development of a risk-based maintenance (RBM) strategy for a power-generating plant. J Loss Prev Process Ind 2005;18:69-81.

25 Wang Y, Cheng G, Hu H, Wu W. Development of a risk-based maintenance strategy using FMEA for a continuous catalytic reforming plant. J Loss Prev Process Ind 2012;25:958-965.

26 Cohen AC. Maximum likelihood estimation in the Weibull distribution based on complete and on censored samples. Technometrics 1965;7:579-88.

27 Al-Fawzan MA. Methods for estimating the parameters of the Weibull distribution. King Abdulaziz City for Science and Technology, Riyadh, Saudi Arabia. 2000;91.

28 Jardine AKS, Tsang AHC. Maintenance, replacement, and reliability: theory and applications: CRC press 2013.

29 Jardine AKS. Maintenance Replacement and Reliability. Great Britain: Pitman Publishing 1973.

30 Wang $\mathrm{C}-\mathrm{H}, \mathrm{Wu} \mathrm{H}-\mathrm{S}$. A novel framework to evaluate programmable logic controllers: A fuzzy MCDM perspective. J Intell Manuf 2014:1-10.

31 Caputo AC, Pelagagge PM, Salini P. AHP-based methodology for selecting safety devices of industrial machinery. Safety Science. 2013;53:202-218.

$32 \mathrm{Wu} \mathrm{W}-\mathrm{H}$, Chiang C-T, Lin C-T. Comparing the aggregation methods in the analytic hierarchy process when uniform distribution. WSEAS Trans Bus Econ 2008;5:74-80.

33 Saaty TL. The Analytical Hierarchy Process. New-york: McGraw-Hill 1980.

34 Emovon I, Norman RA, J MA, Pazouki K. An integrated multicriteria decision making methodology using compromise solution methods for prioritising risk of marine machinery systems. Ocean Eng 2015;105:92-103.

35 Rao RV, Patel BK. A subjective and objective integrated multiple attribute decision making method for material selection. Mater Des 2010;31:4738-4747.

36 Emovon I, Norman RA, Murphy AJ. A new Tool for Prioritising the Risk of Failure Modes for Marine Machinery Systems. In: Proceedings of the 33rd International 
Conference on Ocean, Offshore and Arctic Engineering, California, United States, June 8-13, 2014: ASME.

37 Khorshidi R, Hassani A. Comparative analysis between TOPSIS and PSI methods of materials selection to achieve a desirable combination of strength and workability in Al/SiC composite. Mater Des 2013;52:999-1010.

38 O'Connor P. Practical Reliability Engineering. New york: John Wiley and Sons 1985.

39 Wang H. A survey of maintenance policies of deteriorating systems. Eur J Oper Res 2002;139:469-489.

40 Ahmad R, Kamaruddin S, Azid IA, Almanar IP. Preventive replacement schedule: a case study at a processing industry. Int J Ind Sys Eng 2011;8:386-406.

41 Liang W, Pang L, Zhang L, Hu J. Reliability-centered maintenance study on key parts of reciprocating compressor. In: IEEE International conference on Quality, Reliability, Risk, Maintenance, and Safety Engineering Chengdu, China, March 17-20, 2012. pp. 414-418: IEEE.

42 Alexander D. Application of Monte Carlo simulations to system reliability analysis. In: Proceedings of the 20th International Pump Symposium, Houston, TX; March 17-23; 2003.

43 Rausand M, Vatn J. Reliability Centered Maintenance. In: Soares CG, ed. Risk and Reliability in Marine Technology. Balkema Holland 1998.

44 Perakis AN, Inözü B. Optimal maintenance, repair, and replacement for Great Lakes marine diesels. Eur J Oper Res 1991;55:165-182.

45 Wong EL, Jefferis T, Montgomery N. Proportional hazards modeling of engine failures in military vehicles. J Qual Maint Eng 2010;16:144-155.

46 Jee D-H, Kang K-J. A method for optimal material selection aided with decision making theory. Mater and Des. 2000;21 (3):199-206. 